\title{
GPS AND GIS BASED N-MAPPING OF AGRICULTURAL FIELDS' SPATIAL VARIABILITY AS A TOOL FOR NON-POLLUTING FERTILIZATION BY DRIP IRRIGATION
}

\author{
P. DIOUDIS ${ }^{1}$, A.G. FILINTAS ${ }^{1} \&$ E. KOUTSERIS ${ }^{2}$ \\ ${ }^{1}$ Department of Agricultural Engineering \& Irrigation, Technological Educational Institute of Larissa, Greece. \\ ${ }^{2}$ Department of Planning and Regional Development, University of Thessaly, Greece.
}

\begin{abstract}
A study on nitrates' spatial variability using GPS and GIS processing and mapping, and the effects of drip irrigation interval and applied nitrogen fertilizer, in the movement, concentration and depletion of total $\mathrm{N}$, $\mathrm{NO}_{3}-\mathrm{N}$ and $\mathrm{NH}_{4}-\mathrm{N}$ in the soil and concretely in the active rhizosphere of maize cultivation showed serious infield variability in an experimental field at the Technological Educational Institute of Larissa, Thessaly Valley, Central Greece, in the farming period of the year 2001. Experimental variables were three irrigation frequencies and four nitrogen applications. For crop, corn was selected because it has high nitrogen requirement, which increases the potential for nitrate leaching. Three treatments (i.e. irrigation per 2, 5 and 9 days) were applied in a four replication, randomized complete block design with systematic plot arrangement. The randomization has been done with the method of statistical tables. The N source was an NPK fertilizer at the beginning of cultivation period (first dosage) at a rate of $89.6 \mathrm{~kg} \mathrm{~N} / \mathrm{ha}$ (or $31.48 \%$ of the applied total nitrogen) as basic fertilization and urea $(46 \% \mathrm{~N})$ applied three times (second, third and fourth dosage) with a hydro-fertilization system (fertigation) in irrigation water, at a rate of $65 \mathrm{~kg} \mathrm{~N} / \mathrm{ha}$ (or $22.84 \%$ of the applied total nitrogen) through the drip irrigation system at the root zone. Spatial evaluation, analysis and classification at field (treatments) level derived nitrogen management zones. Results showed that nitrogenous fertilizers and irrigation water require careful management in order to minimize the dangers of $\mathrm{NO}_{3}-\mathrm{N}$ leaching under the root zone in irrigated cultivations of maize. The present study correlates irrigation frequency and soil nitrogen depletion with nitrate concentration GIS maps showing nitrates' spatial variability and also attempts to formulate a more precise and environmental friendly management scheme with variable rate technology farm machinery and precision agriculture.

Keywords: drip irrigation, geostatistical analysis, GIS, GPS, irrigation frequency, maize, nitrogen mapping, soil sampling, spatial variability, variable rate technology.
\end{abstract}

\section{INTRODUCTION}

Plant production has for several years responded positively to a continuous increase in nitrogen application. Nitrate in the soil solution is immediately available and thus acts quickly but is most liable to leaching. This occurs because the additional quantities of nitrogen that are applied in the various cultures are moved with inflow of surface and underground aquatic recipients with the leach.

Principal recognized pollutants that cause the eutrophication phenomenon are nitrogen and phosphorus that are released from different sources: urban, agriculture and livestock are the main sectors that originate nutrient loads carried to the sea [1]. The combined application of irrigation and nitrogen through hydro-fertilization systems (fertigation) is now becoming a common practice in modern agriculture because of its advantages over conventional methods.

Nitrates can leach from the soil into underground aquifers, contaminating well water. The extent of nitrate contamination, and how quickly it occurs, depends on both soil type and depth of the water source. Soil texture affects $\mathrm{NO}_{3}-\mathrm{N}$ leaching. Nitrates can leach more easily in light sandy soils than in clay-based soils [2,3]. Soils have varied retention properties depending on their texture and organic matter content. Although $\mathrm{NO}_{3}$ is an anion that can readily leach through the soil profile, soils with significant quantities of silt, clay and organic matter will retain more $\mathrm{NO}_{3}-\mathrm{N}$ than soils without much silt and clay [4]. 
Nitrogenous fertilizers and irrigation water require careful management in order to minimize the dangers of $\mathrm{NO}_{3}-\mathrm{N}$ leaching under the root zone in irrigated fields of maize [5]. The loss of nutrients through leaching is determined by climatic factors and soil-nutrient interactions. In regions where water percolation is high, the potential for leaching is also high. In such areas percolation of excess water is the rule, providing opportunities for nutrient removal [3]. The extensive use of fertilizers on row crops is considered as a main source of nitrate leaching to ground water, particularly in sandy soils [6].

As for the culture of maize in Greece, it covers an extent of 266,700 ha [7], that is, $5 \%$ of the total cultivated extent. In 2001, the mean production of maize in Greece was $9676 \mathrm{~kg} / \mathrm{ha}$ [6]. Regarding the irrigation of maize, the requirements in water oscillate from 500 until $800 \mathrm{~m}^{3}$ of water per $1000 \mathrm{~m}^{2}$, for the achievement of maximum production by a variety of medium maturity of seed [8]. Corn cultivation requires large quantities of water seasonally, if it is to yield a large crop [9]. Various other research scientists $[3,6,10-16]$, who have carried out extensive studies on the effect of irrigation in the cultivation of corn, drew the same conclusion, that is, irrigation is of the utmost importance, from the appearance of the first silk strands until the milky stage in the maturation of the kernels on the cob. Once the milky stage has occurred, the appearance of black layer development on $50 \%$ of the corn kernels is a sign that the crop has fully ripened, according to Rench and Shaw [15] and Danalatos [16] who carried out research in an experimental field in Greece. The aforementioned criterion was used in the experimental plot for the total irrigation process.

In a corn irrigation study, Dioudis et al. [2] examined the effect of the refilled scheme of the soil moisture depletion on the $\mathrm{NH}_{4}-\mathrm{N}$ and $\mathrm{NO}_{3}-\mathrm{N}$ movement and distribution along the root zone. The measured data indicated that refillment of soil water to the level of field capacity per 2, 5 and 9 days did not change significantly the concentrations of $\mathrm{NH}_{4}-\mathrm{N}$ and $\mathrm{NO}_{3}-\mathrm{N}$ at different soil depths [2].

According to Hatzopoulos [17], the term Geographic Information System (GIS) represents a system that is composed of units of information technology controlled from a computer and has the abilities of concentration, storage, processing and presentation of that information (data) that is referred in specific geographic locations. The structure of GIS consists of a database that manages cartographic elements such as topographic and photogrammetric measurements, digitalizations of maps, etc., and a relational database that manages conventional information, in matrix form, emanating from various sources or from remote sensing analyses and field samplings [17]. Essentially, GIS provides a means of taking many different kinds of information, processing it into compatible data sets, combining it, querying and displaying the results on a map [3]. In conjunction with GIS, the geostatistical methods were developed to create mathematical models of spatial correlation structures $[18,19]$ with a variogram as the quantitative measure of spatial correlation. Advances in electronics and computers generated new techniques to maximize the farmer's profit and to protect the environment. In the later framework, a new technique known as precision agriculture, or precision farming or site-specific management, tries to give solutions [20]. The GIS, Global Positioning System (GPS), telecommunications, computer systems and also geostatistical methods prefix a new form of farm variability management (precision agriculture) [3]. Final objective of precision agriculture is the adaptation of all the farming cares and decisions in the scale of this variability [21]. The bigger the variability of a dependent variable (nitrogen uptake, nitrogen depletion, a chemical property of soil, production of grain, biomass production, etc.) in an agricultural field, the more successful the management practice based on the rules of precision agriculture for the reduction of the variability [14]. The value of spatial information for understanding irrigation and fertility issues and improving decision making is increasingly recognized. As pressures on land and water resources continue to mount, the ability to accurately assess resource conditions and trends becomes more essential. GIS is a powerful information tool at the disposal of decision makers [3]. 
The aim of this project was to carry out research on nitrates' spatial variability using GPS and GIS processing and mapping and the effects of drip irrigation interval and applied nitrogen's fertilizer, in the movement, concentration and depletion of total $\mathrm{N}, \mathrm{NO}_{3}-\mathrm{N}$ and $\mathrm{NH}_{4}-\mathrm{N}$ in the soil and concretely in active rhizosphere of maize cultivation in an experimental field.

\section{MATERIALS AND METHODS}

\subsection{Site description, experimental design and layout description}

\subsubsection{Site description}

The field study was conducted in 2001 at the Technological Educational Institute of Larissa, at Thessaly Valley in Central Greece. The area has an elevation of $83 \mathrm{~m}$ above mean sea level and is situated at $39^{\circ} 37^{\prime} \mathrm{N}$ latitude and $22^{\circ} 22^{\prime} \mathrm{E}$ longitude within the Thessaly plain in the central region of Greece.

\subsubsection{Experimental design and layout description}

Three treatments (i.e. irrigation per 2-(E2), 5-(E5) and 9-(E9) days) were applied in a four replications, randomized complete block design (RCBD) with systematic plot arrangement. The randomization has been done with the method of statistical tables. Each of the four blocks consisted of three treatment combinations allocated in $10 \mathrm{~m} \times 13.3 \mathrm{~m}$ plots. Experimental variables were three irrigation frequencies and four nitrogen applications.

\subsection{Methodology}

\subsubsection{Field experiment}

For crop, corn was selected because it has high nitrogen requirement, which increases the potential for nitrate leaching. The PIONEER-Konstantza variety (Zea mays L.) was sown on 6 April 2001, in rows $75 \mathrm{~cm}$ apart, with plant distances of $17 \mathrm{~cm}$ in the row. In the milky maturation of cob grains, the appearance of black layer in the $50 \%$ of grains of maize constitutes clue that the cultivation has matured completely $[15,16]$. The above criterion was used in the present work for the completion of irrigations. Fertilizer was applied in four dosages. The N source was an NPK fertilizer at the beginning of cultivation period (first dosage) at a rate of $89.6 \mathrm{~kg} \mathrm{~N} / \mathrm{ha}$ (or $31.48 \%$ of the applied total nitrogen) as basic fertilization and urea $(46 \% \mathrm{~N})$ applied three times (second, third and fourth dosage) with a hydro-fertilization system (fertigation) in irrigation water, at a rate of $65 \mathrm{~kg} \mathrm{~N} / \mathrm{ha}$ (or $22.84 \%$ of the applied total nitrogen) through drip irrigation system at root zone. Irrigation water was applied to maize with drip laterals placed every second row and emitters (internal spiral line distributors placed $0.5 \mathrm{~m}$ apart) dripping at a constant (low) discharge of $4 \mathrm{l} / \mathrm{h}$. System operating pressure was 1.215 bar. The soil moisture depletion was refilled at the level of field capacity for every treatment and the later was based on the measurements of the cumulative evapotranspiration with the use of an evaporation class A pan. The water losses were calculated using the time domain reflectometry method, which is a non-radioactive method that is fast and independent of the type of soil $[2,22]$, by daily measurements, and the exhaustion of available moisture was also calculated daily. On 3 September 2001, corn grain and stalk were harvested.

\subsubsection{Soil sampling}

The sampling procedure was used to extract soil samples in 40 locations of the field (in a grid scheme) with auger-hole method and at the same time two GPS monitors were used to log spatial data for the sampled locations in the Greek Geodetic System of Reference (EGSA87) (Projection Type: Transverse Mercator, Spheroid name: GRS 1980 and datum: EGSA87). The corresponding 
soil depths were $0-30,30-60$ and 60-90 cm. The soil samples were used to determine the concentrations of $\mathrm{NH}_{4}-\mathrm{N}, \mathrm{NO}_{3}-\mathrm{N}$ and total nitrogen by laboratory methods. The concentrations were measured at three stages, preceding (30 March), at the middle of the growing (emergence) stage (15 July) and after harvesting (4 September).

\subsubsection{Data processing and map development}

In general, what makes GIS different from other kinds of computer mapping systems is that the attribute data and spatial information are always linked and processed jointly in GIS [3]. By the use of GIS and geostatistical methods, one can develop methods to create mathematical models of spatial correlation structures with a semivariogram as the quantitative measure of spatial correlation $[18,19]$.

A critical issue to the analysis of spatial information is the ability to reliably estimate and present its spatial variability from point input data. A powerful approach to achieve this objective is the one advanced by the geostatistics, where a continuous surface representing a given variable (e.g. in the present paper $\mathrm{NO}_{3}-\mathrm{N}, \mathrm{NH}_{4}-\mathrm{N}$ and total nitrogen) is calculated from point data based on the potential presence of correlation among data points as a function of the modulus and direction of vector separating them from each other. This relationship, known as spatial continuity, is an important characteristic of spatial data that can provide significant insight into the nature of the physical phenomena under study.

So, by the use of soil sampling and laboratory analysis, GPS verification, GIS, geostatistical methods and computer data processing, the nitrates' concentrations were mapped in digital form in EGSA87 for spatial evaluation and analysis at the field level in order to derive conclusions for the effects of drip irrigation water and applied nitrogen fertilizer effects in the movement, concentration and allocation of nitrates in the active rhizosphere of maize cultivation.

\section{RESULTS AND DISCUSSION}

The mean monthly temperature for the observed year ranges from $7.2^{\circ} \mathrm{C}$ in January to $28.4^{\circ} \mathrm{C}$ in July (Fig. 1). The annual rainfall for the observed year was $346.0 \mathrm{~mm}$ with only $21.99 \%$ falling in rainy season (September-December) (Fig. 1).

The effective monthly rainfall and the mean monthly rainfall in the year 2001 are depicted in Fig. 2. The study area has a Mediterranean climate with a warm dry summer and a mild winter and is designated as 'Csa' according to the Koeppen [3] climatic classification. The topography of the area is flat and the type of soil is clay, which has a $\mathrm{pH}$ 7.5. The particle size distribution of soil is clay $46.00 \%$, silt $25.50 \%$ and sand $28.50 \%$. The mean values of pertinent physical properties of the experimental clay soil were: bulk density $1.42 \mathrm{~g} / \mathrm{cm}^{3}$, field capacity $31.21 \% \mathrm{wt}$, permanent wilting point $17.14 \% \mathrm{wt}$, saturated conductivity $3.0 \times 10^{-5} \mathrm{~cm} / \mathrm{s}$ at $15 \mathrm{~cm}$ depth and $3.2 \times 10^{-5} \mathrm{~cm} / \mathrm{s}$ at $45 \mathrm{~cm}$ depth (measured with the Guelph parameter).

The results of laboratory analyses of soil samples for the first sampling date are depicted in Fig. 3a for 2001; they show the levels of residual nitrogen after the farming period of 2000 and before seeding for the farming period of 2001. Figure $3 \mathrm{~b}$ and $\mathrm{c}$ shows for the second and third soil sampling the mean concentrations of the plots for each of the three irrigation treatments (refilled water deficit per 2, 5 and 9 days, for each depth).

Sampling and spatial data were processed by computer processing, GIS and geostatistical methods. Irrigation and soil data, at the stage of computer processing, sustained suitable transformation so that they were formed and impressed spatially, giving the corresponding field zones of total $\mathrm{N}, \mathrm{NO}_{4}-\mathrm{N}$, $\mathrm{NO}_{3}-\mathrm{N}$ and irrigation treatment.

The $\mathrm{NO}_{3}-\mathrm{N}$ and $\mathrm{NH}_{4}-\mathrm{N}$ GIS maps, which were constructed, indicated that there is a serious spatial variability of nitrogen concentrations (NCs) in the experimental field plots. It was observed that the 


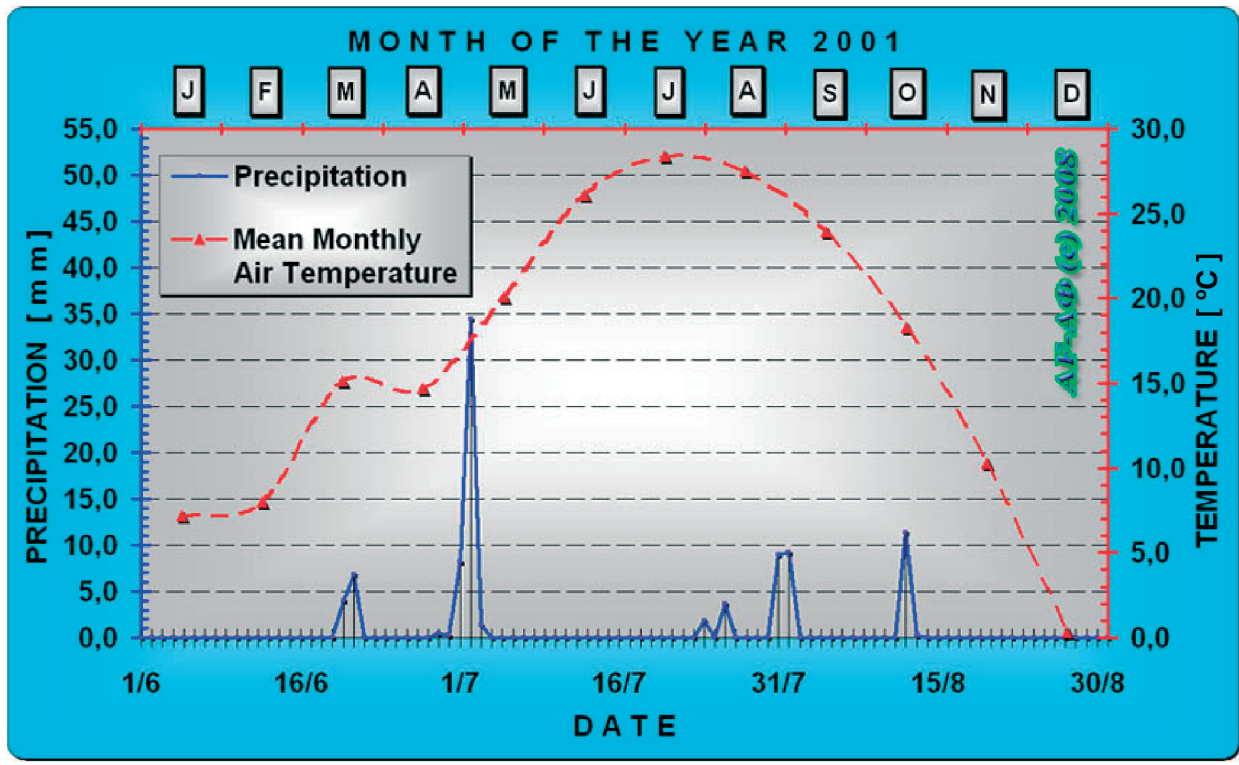

Figure 1: Precipitation during irrigation period and mean monthly air temperatures of the year 2001.

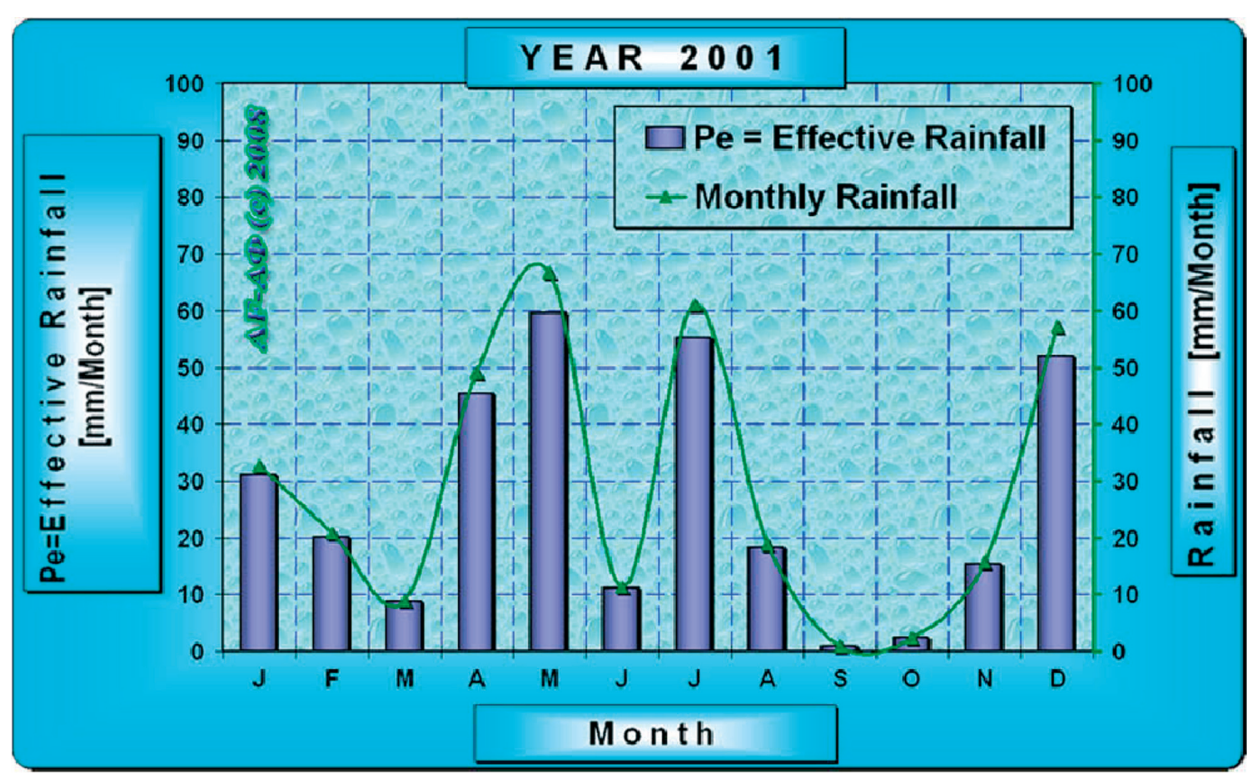

Figure 2: Effective monthly rainfall and mean monthly rainfall of the year 2001. 

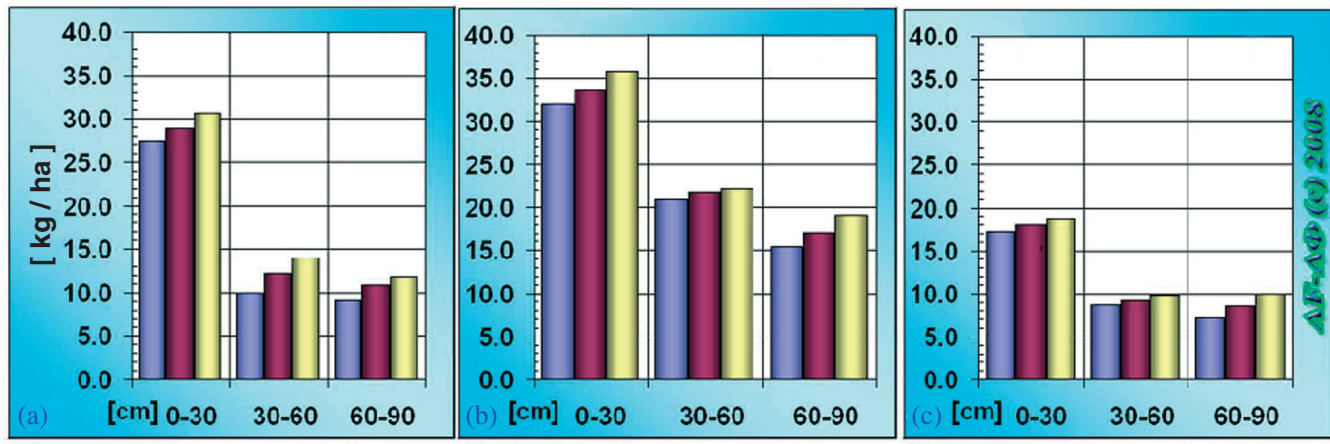

Total N Mean of E2 Total N Mean of E5

Total N Mean of E9

Figure 3: Mean values of concentrations for treatments E2, E5, E9 (in kg/ha) of total $\mathrm{N}\left(\mathrm{NO}_{3}-\mathrm{N}+\mathrm{NH}_{4}-\mathrm{N}\right)$ at each soil depth of 0-30, 30-60 and 60-90 cm, for the (a) first, (b) second and (c) third soil sampling.

$\mathrm{NO}_{3}-\mathrm{N}$ and $\mathrm{NH}_{4}-\mathrm{N}$ concentrations were very close. The results of total $\mathrm{NC}$ GIS mapping for the experimental field for the first sampling appear in Fig. $4 \mathrm{a}$ and $\mathrm{b}$.

Figure 4a shows the NC at 0-30 cm depth and Fig. 4b shows the NC at 30-60 cm depth, for treatments E2, E5 and E9, considering the $0-60 \mathrm{~cm}$ active root zone of corn crop. The above figures are the result of the GIS software, using the Smart quantiles classification method on the measured 0-30 and 30-60 cm NC, and 10 nitrogen classes (zones) were created for each corresponded range for the three sampling dates.

From the NC maps of the first sampling, we distinguish broadly two different NC zones. For the 0-30 cm depth, one NC zone between 29.67 and $37.98 \mathrm{~kg} / \mathrm{ha}$ extended from the center of the experimental field to its south-northwest and the other NC zone between 23.59 and $29.67 \mathrm{~kg} / \mathrm{ha}$ situated in the northeast corner of the field, in the southeast and in southwest ones. For the 30-60 cm depth, one $\mathrm{NC}$ zone between 11.94 and $16.19 \mathrm{~kg} /$ ha extended from the center of the experimental field to its southnorthwest and the other $\mathrm{NC}$ zone between 9.50 and $11.94 \mathrm{~kg} / \mathrm{ha}$ situated in the northeast corner of the field, in the southeast and in southwest ones. Approximately, the same pattern is kept for the second and third sampling, indicating a uniform nitrogen depletion through nitrogen uptake and nitrogen leaching and seems that the irrigation treatments does not differentiate considerably the redistribution of NC for the second and third sampling correspondingly. It is worth mentioning here that the NC maps for the first, second and third sampling were based on three completely different ranges of NC, for each soil depth.

The first NC map (residual nitrogen) was based on the $23.59-37.98 \mathrm{~kg} / \mathrm{ha}$ range for the $0-30 \mathrm{~cm}$ depth and the second NC map was based on the $9.50-16.19 \mathrm{~kg} / \mathrm{ha}$ range for the $30-60 \mathrm{~cm}$ depth. The third NC map (Fig. 5a) was based on the $20.93-52.50 \mathrm{~kg} / \mathrm{ha}$ range for the $0-30 \mathrm{~cm}$ depth and the fourth NC map (Fig. 5b) was based on the 13.78-34.56 kg/ha range for the 30-60 cm depth, after the first, second and third dosage of nitrogen were applied $(21.96 \mathrm{~kg}$ of N/ha). The fifth NC map was based on the $11.53-27.11 \mathrm{~kg} / \mathrm{h}$ a range for the $0-30 \mathrm{~cm}$ depth and the sixth NC map was based on the $6.18-14.53 \mathrm{~kg} / \mathrm{ha}$ range for the $30-60 \mathrm{~cm}$ depth, after harvesting.

To avoid creating NC maps for different classes and ranges, and in order to compare nitrogen's spatial variability using specific meaningful values, the software is customized to create six nitrogen management zone (NMZ) maps (with defined interval classification method), with nine nitrogen classes (zones) instead of 10 and with uniform range of each class, for all maps as shown in 


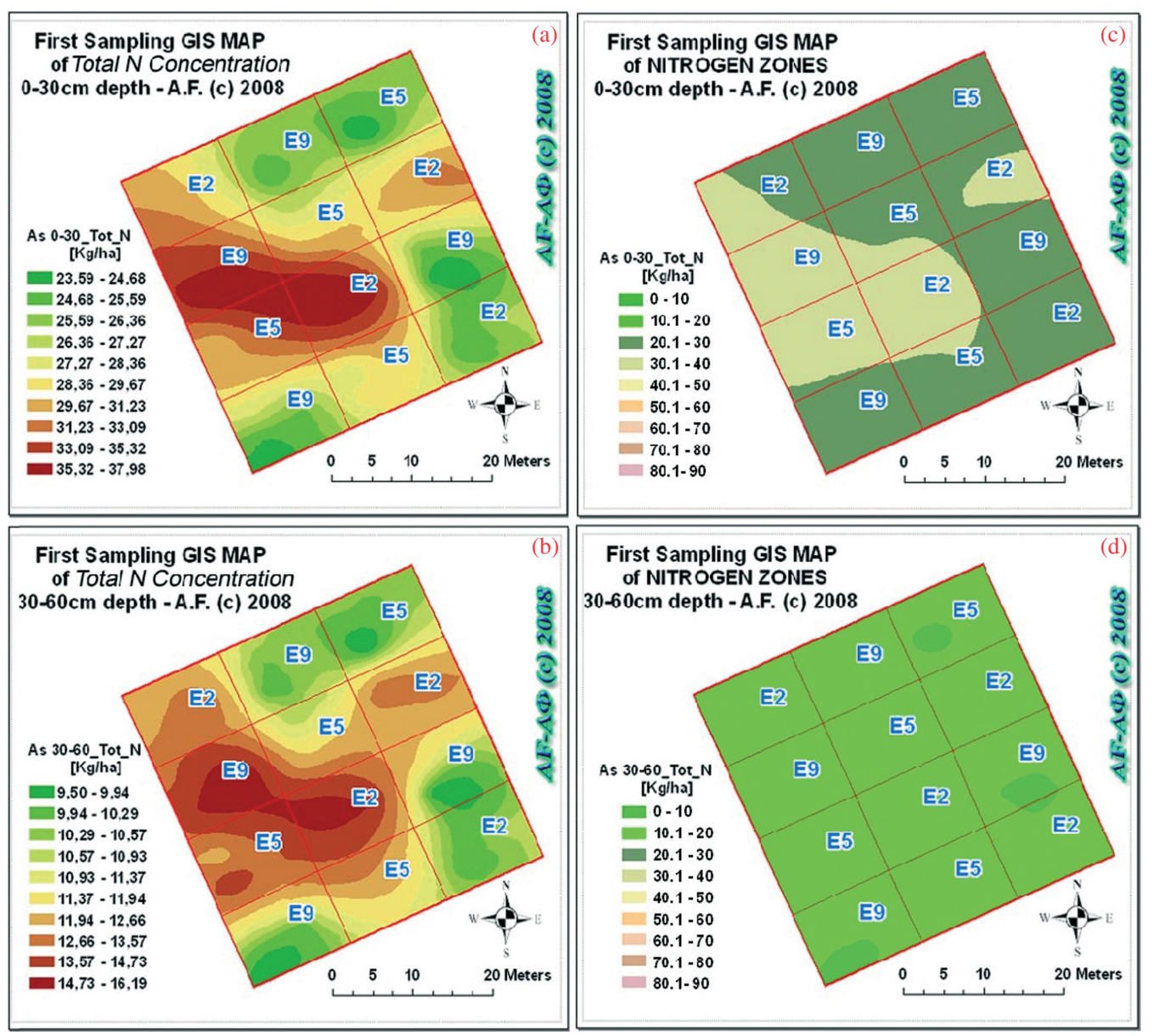

Figure 4: $(\mathrm{a}$ and b) GIS maps for treatments E2, E5 and E9 for the first soil sampling of total N $(\mathrm{kg} /$ ha) concentration at (a) 0-30 cm and (b) 30-60 cm depth. (c and d) GIS maps of total nitrogen zones for (c) 0-30 cm and (d) 30-60 cm soil depth.

Figs 4(c, d), 5(c, d), 6(c, d) and 7b. The defined interval classification scheme allows the user to specify an interval by which to equally divide a range of attribute values [3, 17, 23]. This classification method is used if the user is looking for features that meet a specific criterion, or if we are comparing features to specific, meaningful values [3]. To do this, we specified the upper and lower limit for each class.

Figure $4 \mathrm{c}$ and d shows the NMZs at $0-30$ and 30-60 $\mathrm{cm}$ depth, based on the residual nitrogen measurements of first sampling. Figures 5(c,d) and 6(c,d) show NMZs for the second and third sampling, respectively. Finally, Fig. 7b shows the total NMZs for the third sampling at $0-60 \mathrm{~cm}$ depth soil profile of corn active root zone. The same pattern appears and we distinguish again two different NC zones, situated in the same parts of the experimental field. A high one extended from the center to its south-north and the other one in the northeast as well as in the southeast and southwest corner. Keeping the same range of NC for the three sampling times, it is easy to see the level of NC, as it is changed through out the cultivation period and after the additions (fertilization) and losses of nitrogen (uptake and leaching). 


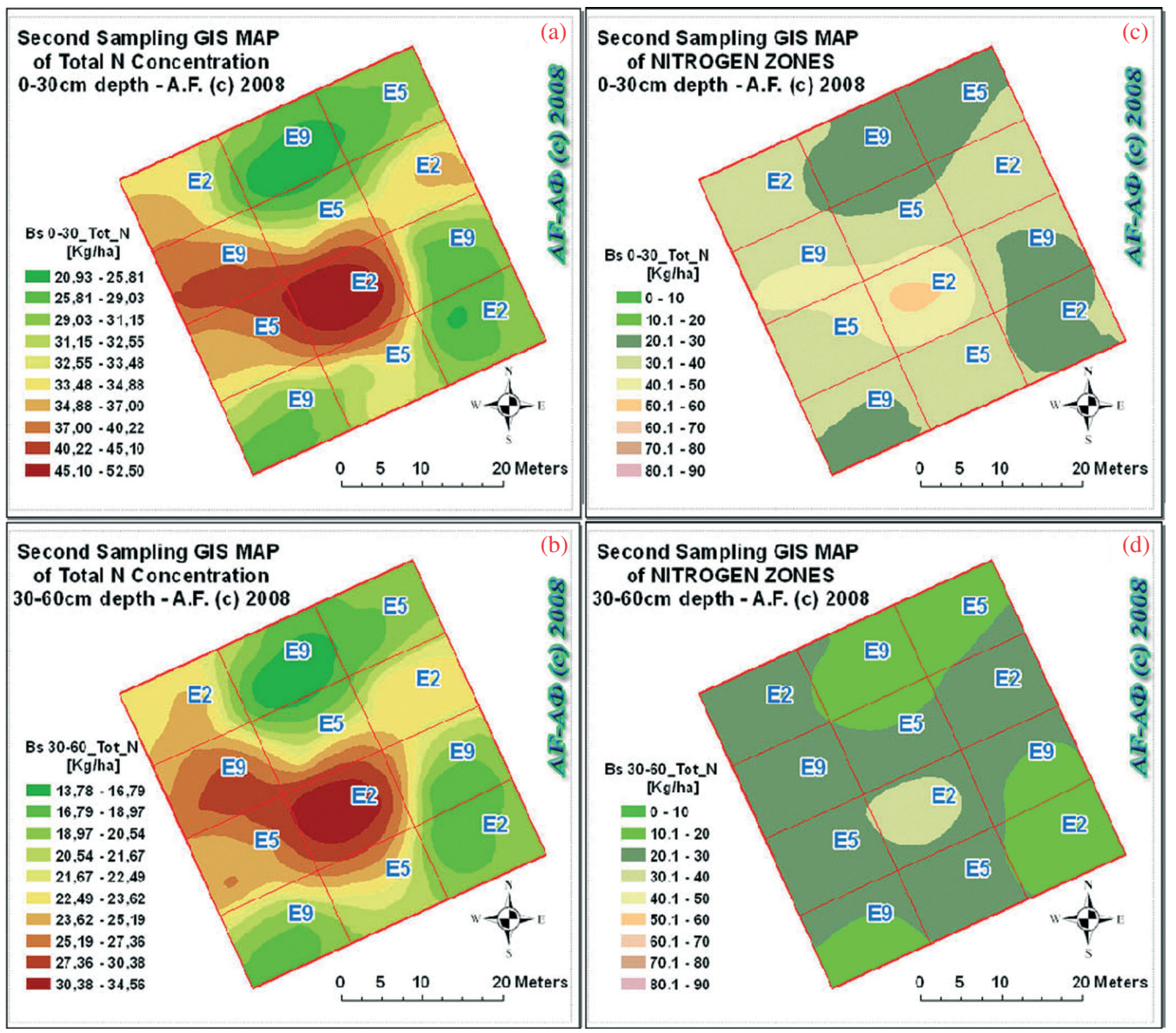

Figure 5: (a, b) GIS maps for treatments E2, E5 and E9 for the second soil sampling of total N (kg/ha) concentration at (a) 0-30 cm and (b) 30-60 cm depth. (c, d) GIS maps of total nitrogen zones for (c) 0-30 cm and (d) 30-60 cm soil depth.

As for the total available nitrogen before seeding-fertilization and at depth 0-60 cm, it was found that it had a variability which fluctuated between 33.08 and $53.27 \mathrm{~kg}$ N/ha in the various nitrogen zones (VNZs). After the first $\mathrm{N}$-application, the theoretically available $\mathrm{N}$ was estimated to reach between 122.6 and $142.9 \mathrm{~kg} \mathrm{~N} / \mathrm{ha}$ in the VNZs. On 8 June, 6 July and $16 \mathrm{July}$, the second, third and fourth $\mathrm{N}$-application dose with urea fertigation (UF) were applied, with $65 \mathrm{~kg} \mathrm{~N} / \mathrm{ha}$ each.

The total NC GIS maps of the second soil sampling confirm the nitrogen addition (Fig. 5a and b). Results of the third soil sampling (Figs 6(a,b) and 7a) indicated a field variability in total nitrogen residual between 17.71 and $41.64 \mathrm{~kg} \mathrm{~N} / \mathrm{ha}$. The latter means that the corn plants took an amount of $\mathrm{N}$ between 296.2 and $299.9 \mathrm{~kg} \mathrm{~N} / \mathrm{ha}$ in the VNZs, when a mean consumption of about $316.7 \mathrm{~kg} \mathrm{~N} / \mathrm{ha}$ for a mean yield of $15836.33 \mathrm{~kg} / \mathrm{ha}$ of corn grain was expected.

Deriving NMZs from NC GIS maps of the experimental field leads the way to a more precise, variant and environmentally friendly management in each NMZs, which can give better farming results such as decreasing field variability, increasing the mean yield among plots [14], reduction of 


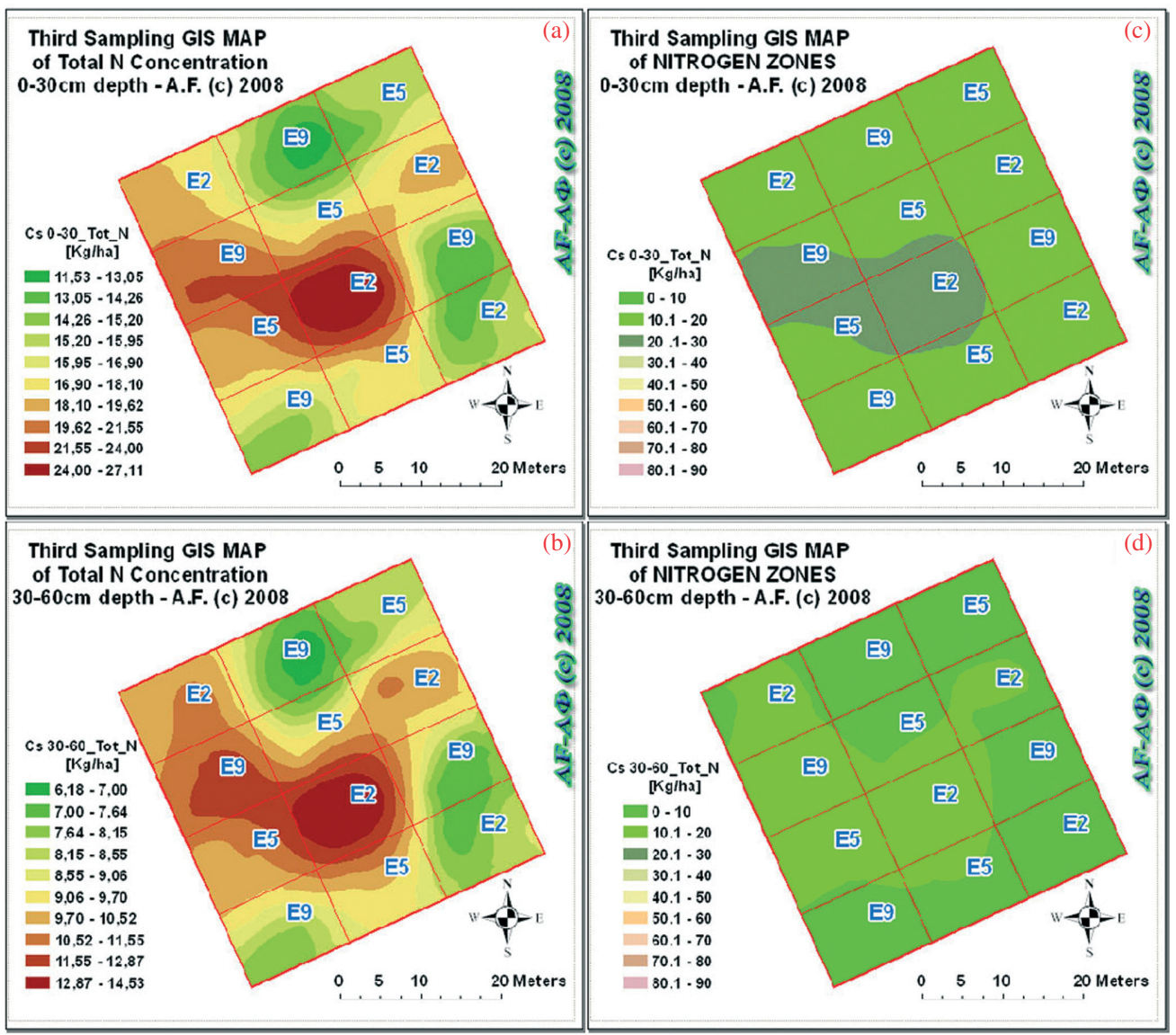

Figure 6: (a, b) GIS maps for treatments E2, E5 and E9 for the third soil sampling of total N (kg/ha) concentration at (a) 0-30 cm and (b) 30-60 cm depth. (c, d) GIS maps of total Nitrogen Zones for (c) 0-30 cm and (d) $30-60 \mathrm{~cm}$ soil depth.

nitrate leaching, environmental water resources protection against nitrate pollution $[2,3,14]$ and economy in farm expenses [3, 14].

It was interesting to see and explain the variability in the NC maps and to find its cause. Such variability can be explained by possible reasons such as variability of soil properties (texture, chemical and physical properties), variability of plant populations and soil microtopography which could affect nitrogen uptake from the plants in the VNZs.

The samples' total nitrogen contents in $\mathrm{kg} / \mathrm{ha}$ for the first, second and third soil sampling are presented in Fig. 3a, b and c, respectively.

The summary statistics of total nitrogen at soil depths 0-30, 30-60 and 0-60 cm (three sets) are presented in Table 1. Each measurement represents a single soil sample collected in the field, handled and analyzed in the laboratory as stated before.

By observing and analyzing Figs 3(a-c), 4(a, b), 5(a, b), 6(a, b) and Table 1, we observe that in the top soil layer (0-30 cm depth) we encounter higher NCs and higher spatial variability in relation to the deeper soil layer (30-60 cm depth). 


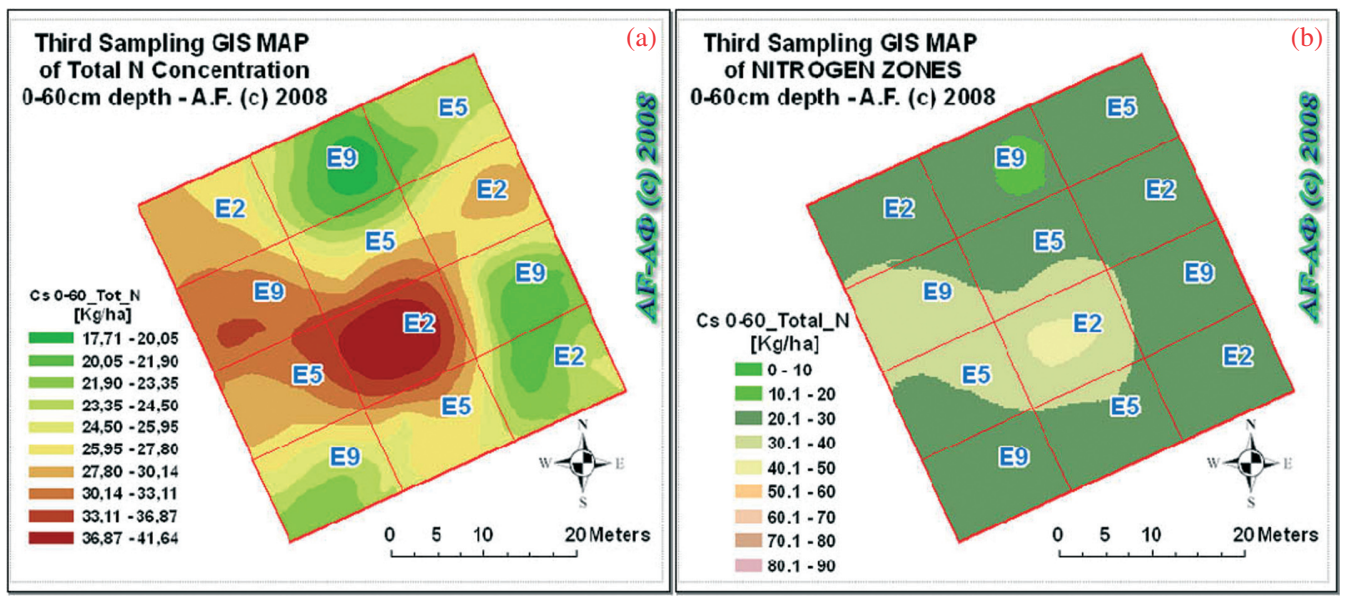

Figure 7: GIS map for treatments E2, E5 and E9 at 0-60 cm depth for (a) third sampling of soils' total $\mathrm{N}$ (kg/ha) concentration; (b) nitrogen zones for third soil sampling.

Table 1: Total nitrogen summary statistics of the soil samples.

\begin{tabular}{lccc}
\hline $\begin{array}{l}\text { Parameter data of } \\
\text { third soil sampling }\end{array}$ & \multicolumn{3}{c}{ Total N } \\
\cline { 2 - 4 } & $0-60 \mathrm{~cm}$ & $30-60 \mathrm{~cm}$ & $0-30 \mathrm{~cm}$ \\
\hline $\mathrm{N}$ (count) & 40 & 40 & 40 \\
Minimum & 17.713 & 6.1818 & 11.531 \\
Maximum & 41.645 & 14.534 & 27.111 \\
Mean & 26.936 & 9.5781 & 17.536 \\
Standard deviation & 5.2992 & 1.9241 & 3.4498 \\
First quartile & 23.610 & 8.2398 & 15.370 \\
Median & 26.142 & 9.3862 & 17.018 \\
Third quartile & 28.606 & 10.511 & 18.622 \\
\hline
\end{tabular}

In geostatistical analysis, selecting a semivariogram model is an iterative process that involves calculating experimental semivariograms, fitting an alternative semivariogram, calculating an alternative ordinary Kriging prediction surface and carrying out a cross-validation statistical analysis to assess the performance of the prediction surface in terms of unbiasedness and estimation of uncertainty. In the cross-validation process, a data point is removed from the data set and its value is estimated from the rest of the data points. The process is repeated in succession for all the data points.

The geostatistical model selection criteria were the mean standardized prediction error (MSPE) as a measure of unbiased predictions $[3,17,18]$ and the root mean square standardized prediction error (RMSSPE) as a measure of correctly assessing the variability of prediction [3, 18, 19]. MSPE and RMSSPE were used to assess the unbiasedness and the estimation of uncertainty, respectively. The MSPE and RMSSPE are defined as follows: 


$$
\begin{gathered}
\text { MSPE }=\frac{\sum_{i=1}^{n-1}\left(Z^{*}\left(x_{i}\right)-z\left(x_{i}\right)\right) / \sigma^{*}\left(x_{i}\right)}{n-1}, \\
\text { RMSSPE }=\sqrt{\frac{\sum_{i=1}^{n-1}\left[\left(Z^{*}\left(x_{i}\right)-z\left(x_{i}\right)\right) / \sigma^{*}\left(x_{i}\right)\right]^{2}}{n-1},}
\end{gathered}
$$

where $Z^{*}\left(x_{i}\right)$ is the estimated value of the variable at location $x_{i}, \sigma^{*}\left(x_{i}\right)$ is the standard error of the variable at location $x_{i}$ and both values are based on the other $n-1$ data points.

The objective of the structural and geostatistical analysis process is to obtain an MSPE value close to zero $(\approx 0)$, which indicates unbiasedness of prediction errors, and an RMSSPE value close to one $(\approx 1)$, which indicates accurate estimation of prediction variability.

Based on structural and geostatistical analysis, a spherical model (range $=18.12 \mathrm{~m}$; sill $=36.222$; nugget $=0$ ) was selected for the NC semivariogram of the third sampling (Fig. 8a). From the NC and NMZ GIS map results (Figs $7(a, b)$ ) of the third sampling, and also from the data for geostatistical measures (geostatistical variogram, histogram, etc.) and the cross-validation with measured versus predicted data (Fig. $8(\mathrm{a}-\mathrm{d})$ ), for the three irrigation treatments a MSPE $=0.0183$ and a RMSSPE $=0.678$ were determined.

The regression model of third sampling data and map ( $\mathrm{NC} \mathrm{kg} / \mathrm{ha}$ ) for the depth $0-60 \mathrm{~cm}$ is shown in eqn (3):

$$
Y_{\text {Predicted }}=0.662 X_{\text {Measured }}+8.893 \text {. }
$$

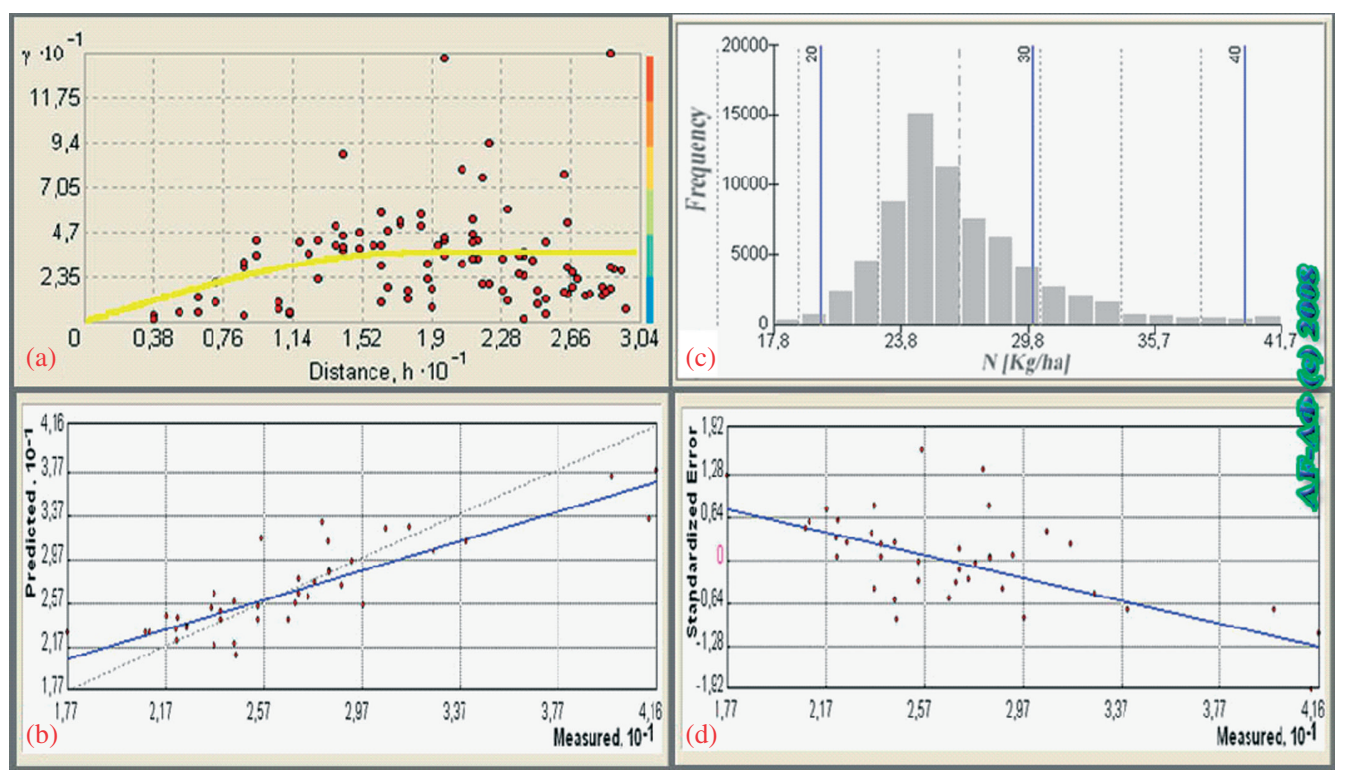

Figure 8: For third sampling: (a) geostatistical variogram; (b) cross-validation with measured vs predicted data; (c) histogram of the predicted data; (d) standardized error vs measured data. 
The regression model of third sampling data and map ( $\mathrm{NC} \mathrm{kg} / \mathrm{ha})$ for the soil depth $0-30 \mathrm{~cm}$ is shown in eqn (4):

$$
Y_{\text {Predicted }}=0.683 X_{\text {Measured }}+5.378
$$

The regression model of third sampling data and map ( $\mathrm{NC} \mathrm{kg} / \mathrm{ha}$ ) for the soil depth $30-60 \mathrm{~cm}$ is shown in eqn (5):

$$
Y_{\text {Predicted }}=0.646 X_{\text {Measured }}+3.391 \text {. }
$$

The criteria results for the MSPE as a measure of unbiased predictions $[3,17,18]$ and for the RMSSPE as a measure of correctly assessing the variability of prediction $[3,18,19]$ are presented in Table 2. Moreover, in Table 3 are presented the soil sample IDs and the results of measured and predicted $\mathrm{N}$ values and MSPE values for the third soil sampling at 0-60 cm soil depth.

Statistical analysis using SPSS program, for the third sampling measured data, for the 2001 cultivation period of the experimental corn field, indicated that refillment of soil water to the level of field capacity per 2, 5 and 9 days did not change significantly (significance level 0.05 ) the concentration of total residual nitrogen $(P=0.063), \mathrm{NH}_{4}-\mathrm{N}(P=0.065)$ and $\mathrm{NO}_{3}-\mathrm{N}(P=0.066)$ at the depth of $0-60 \mathrm{~cm}$

This occurred because

- The irrigation method did not create a water surplus that could wash away the nitrates.

- Precipitation during the irrigation period had a low range, except for 1 day (2 July) and it had quite a normal distribution, so it did not affect nitrates' leaching significantly.

- The fertigation system had a high degree of performance and in conjunction with the excellent performance of the drip irrigation system in the 2-, 5- and 9-day water treatments, it had high spatial water-UF fertilizer application uniformity.

- Fertigation application dates were temporally well distributed, so the corn plants were able to uptake all the nitrogen quantities that were applied in the field leaving finally low concentrations of residual nitrogen in the soil.

From what has been mentioned above and from the criteria results, we concluded that the methods which were used to derive the final NC and also MZs GIS maps lead to a high accuracy resulting in depiction of soil nitrates and residual total nitrogen spatial variability in the experimental agricultural field.

Knowing the cause of the variability is not only the basis for planning variable rate nitrogen applications for the next season's crop but also, and more importantly, for the next fertilizer application in the current season's crop. A sensor-based, on-the-go fertilizer application method could be used with the appropriate variable rate technology (VRT) farm machinery for the basic fertilization application at the beginning of the farming season. Appropriate software should be used to program variable nitrogen rate settings for the nitrogen application with VRT machinery, which should have the ability to change the settings when necessary.

Table 2: Geostatistics criteria results for the third soil sampling.

\begin{tabular}{lccc}
\hline $\begin{array}{l}\text { Parameter data of the } \\
\text { third soil sampling }\end{array}$ & \multicolumn{2}{c}{ Results for the total nitrogen at various soil depths } \\
\cline { 2 - 4 } & $0-30 \mathrm{~cm}$ & $30-60 \mathrm{~cm}$ & $0-60 \mathrm{~cm}$ \\
\hline MSPE & 0.009588 & 0.008744 & 0.0183 \\
RMSSPE & 0.672900 & 0.716700 & 0.6780 \\
\hline
\end{tabular}


Table 3: Measured and predicted $\mathrm{N}$ values and MSPEs for the third soil sampling $(0-60 \mathrm{~cm}$ depth).

\begin{tabular}{lccccr}
\hline Serial number & $\begin{array}{c}\text { Irrigation } \\
\text { treatment }\end{array}$ & Soil sample ID & $\begin{array}{c}\text { Measured N } \\
\text { values }\end{array}$ & $\begin{array}{r}\text { Predicted N } \\
\text { values }\end{array}$ & MSPE \\
\hline 1 & E2 & SS01 & 28.332 & 28.556 & 0.047 \\
2 & E2 & SS02 & 28.332 & 28.396 & 0.018 \\
3 & E2 & SS03 & 29.290 & 29.485 & 0.052 \\
4 & E9 & SS04 & 31.617 & 32.471 & 0.226 \\
5 & E9 & SS05 & 33.943 & 31.159 & -0.736 \\
6 & E9 & SS06 & 27.100 & 27.790 & 0.157 \\
7 & E5 & SS07 & 28.305 & 31.215 & 0.781 \\
8 & E5 & SS08 & 28.879 & 27.229 & -0.441 \\
9 & E5 & SS09 & 32.575 & 30.370 & -0.510 \\
10 & E9 & SS10 & 25.458 & 24.271 & -0.317 \\
11 & E9 & SS11 & 22.583 & 23.684 & 0.235 \\
12 & E9 & SS12 & 23.678 & 21.889 & -0.422 \\
13 & E9 & SS13 & 22.583 & 23.466 & 0.255 \\
14 & E9 & SS14 & 22.133 & 22.259 & 0.034 \\
15 & E9 & SS15 & 30.659 & 32.428 & 0.409 \\
16 & E5 & SS16 & 25.458 & 25.306 & -0.041 \\
17 & E5 & SS17 & 28.058 & 32.926 & 1.331 \\
18 & E5 & SS18 & 23.541 & 25.214 & 0.381 \\
19 & E2 & SS19 & 17.713 & 22.983 & 1.228 \\
20 & E2 & SS20 & 41.645 & 37.628 & -1.099 \\
21 & E2 & SS21 & 39.812 & 37.118 & -0.739 \\
22 & E5 & SS22 & 27.100 & 26.474 & -0.149 \\
23 & E5 & SS23 & 25.594 & 31.561 & 1.612 \\
24 & E5 & SS24 & 24.564 & 20.952 & -0.877 \\
25 & E5 & SS25 & 26.689 & 24.245 & -0.579 \\
26 & E5 & SS26 & 21.762 & 24.485 & 0.745 \\
27 & E5 & SS27 & 41.313 & 33.211 & -1.919 \\
28 & E2 & SS28 & 26.963 & 25.728 & -0.339 \\
29 & E2 & SS29 & 27.784 & 27.533 & -0.069 \\
30 & E2 & SS30 & 23.952 & 24.877 & 0.218 \\
31 & E9 & SS31 & 27.511 & 26.264 & -0.290 \\
32 & E9 & SS32 & 23.952 & 24.169 & 0.039 \\
33 & E9 & SS33 & 23.678 & 26.568 & 0.783 \\
34 & E2 & SS34 & 22.173 & 24.314 & 0.582 \\
35 & E2 & SS35 & 29.701 & 25.528 & -0.862 \\
36 & E2 & SS36 & 21.041 & 23.101 & 0.561 \\
37 & E2 & SS37 & 22.106 & 23.367 & 0.305 \\
38 & E5 & SS38 & 20.875 & 23.068 & 0.457 \\
39 & E2 & SS39 & 24.499 & 21.965 & -0.590 \\
40 & SS40 & 24.499 & 25.868 & 0.252 \\
Mean value & & & 26.936 & 26.978 & 0.018 \\
\hline
\end{tabular}


However, the spatial evaluation and geostatistical analysis [18, 19] at the field level indicated significant (significance level 0.05) spatial autocorrelation of the measured sample points in a range of $18.12 \mathrm{~m}$ at angle directions of $245^{\circ}$ and $65^{\circ}$ which were the directions that basic fertilizer application farm equipment were driven in guidelines among the three treatments. The significant spatial autocorrelation of the measured sample points can lead next season's soil sampling to targeted or zone sampling inside the NMZs (aiming at fewer soil samples as well as decreased sampling and laboratory cost), with the prerequisite that the distance between the sampling points would be smaller than the range of $18.12 \mathrm{~m}$.

\section{CONCLUSIONS}

This study was aimed to monitor the effect of drip irrigation frequency in the movement, concentration and depletion of total $\mathrm{N}, \mathrm{NO}_{3}-\mathrm{N}_{\text {and }} \mathrm{NH}_{4}-\mathrm{N}$ in the soil and concretely in active rhizosphere of maize cultivation in conjunction with nitrates' concentration and MZs GIS maps of the field for non-polluting fertilization. Experimental variables were three irrigation frequencies and four nitrogen applications. For crop, corn was selected because it has high nitrogen requirement, which increases the potential for nitrate leaching. Three treatments (i.e. irrigation per 2, 5 and 9 days) were applied in a four replications, RCBD with systematic plot arrangement. The randomization has been done with the method of statistical tables. The N source was an NPK fertilizer at the beginning of cultivation period (first dosage) at a rate of $89.6 \mathrm{~kg} \mathrm{~N} / \mathrm{ha}$ (or $31.48 \%$ of the applied total nitrogen) as basic fertilization and urea $(46 \% \mathrm{~N})$ applied three times (second, third and fourth dosage) with a hydrofertilization system (fertigation) in irrigation water, at a rate of $65 \mathrm{~kg} \mathrm{~N} / \mathrm{ha}$ (or $22.84 \%$ of the applied total nitrogen) through drip irrigation system at root zone. Spatial evaluation, analysis and classification at field (treatments) level derived NMZs. The $\mathrm{NO}_{3}-\mathrm{N}$ and $\mathrm{NH}_{4}-\mathrm{N}$ GIS maps which were constructed indicated that there is a serious spatial variability of NCs in the experimental field plots. It was observed that the $\mathrm{NO}_{3}-\mathrm{N}$ and $\mathrm{NH}_{4}-\mathrm{N}$ concentrations were very close.

To avoid creating NC maps on different classes and ranges, and in order to compare Nitrogen spatial variability in specific, meaningful values, we created seven NMZ maps (with defined interval classification method), with nine nitrogen classes (zones) and with uniform range of each class, for all maps. We adhered to the defined interval classification scheme because it allows the user to specify an interval by which to equally divide a range of attribute values [3, 17, 23]. This classification method is used if we are looking for features that meet a specific criterion or if we are comparing features to specific, meaningful values [3].

From the NC and NMZ GIS map results (Figs 7(a, b)) of the third sampling, and also from the data for geostatistical measures (geostatistical variogram, histogram, etc.) and the cross-validation with measured versus predicted data (Fig. 8(a-d)), for the three irrigation treatments a MSPE $=0.0183$ and a RMSSPE $=0.678$ were determined. The regression model of third sampling data and map ( $\mathrm{NC} \mathrm{kg} / \mathrm{ha}$ ) for the depth $0-60 \mathrm{~cm}$ is shown in eqn (3). The measured $\mathrm{N}$ value results at a soil depth of 0-60 cm were minimum value $=17.713 \mathrm{~kg} / \mathrm{ha}$, maximum value $=41.645 \mathrm{~kg} / \mathrm{ha}$, mean value $=26.936 \mathrm{~kg} / \mathrm{ha}$ with a standard deviation of 5.2992 .

The predicted $\mathrm{N}$ value results at a soil depth of $0-60 \mathrm{~cm}$ were minimum value $=20.952 \mathrm{~kg} / \mathrm{ha}$, maximum value $=37.628 \mathrm{~kg} / \mathrm{ha}$, mean value $=26.978 \mathrm{~kg} / \mathrm{ha}$ with a standard deviation of 4.1583 .

From what has been mentioned above and from the criteria results, we concluded that the methods used to derive the final NC and MZs GIS maps lead to a high accuracy in depicting the spatial variability of soil nitrates and residual total nitrogen in the experimental field.

Knowing the cause of the variability is not only the basis for planning variable rate nitrogen applications for the next season crop but also more important for the next fertilizer application in 
the current season crop. A sensor-based, on-the-go fertilizer application method could be used with the appropriate VRT farm machinery for the basic fertilization application at the beginning of the farming season. Appropriate software should be used to program variable nitrogen rate settings for the nitrogen application with VRT machinery, which should have the ability to change the settings when necessary.

Finally, the results from this study showed that GPS and GIS nitrogen mapping, as a tool for non-polluting fertilization by drip irrigation, can form the basis for variable rate and non-polluting fertilizer applications in corn crop. It appears that the presented data can assist farmers in the environmentally friendly management of their crops which can give better farming results such as decreasing field variability, increasing the mean yield among plots, reduction of nitrate leaching, protection of environmental water resources against nitrate pollution and farming cost reduction.

\section{REFERENCES}

[1] European Commission, Implementation of Council Directive 91/676/EEC Concerning the Protection of Waters Against Pollution Caused by Nitrates from Agricultural Sources, Office for Official Publications of the European Communities: Luxembourg, pp. 1-44, 2002.

[2] Dioudis, P., Filintas, Ag. \& Pateras, D., Drip irrigation frequency effects on movement and concentration of nitrates on corn crop. Proc. of Scientific Congress on the Management of Aquatic Resources and the Sustainable Development of Thessaly, the 3rd Conference of Thessaly Development, Company of Thessalian Studies, ETHEM, Larissa, Vol. B, pp. 159-171, 2003.

[3] Filintas, T.Ag., Land Use Systems with Emphasis on Agricultural Machinery, Irrigation and Nitrates Pollution, with the Use of Satellite Remote Sensing, Geographic Information Systems and Models, in Watershed Level in Central Greece, MSc Thesis, Department of Environmental Studies, University of Aegean, Mitilini, Greece, 2005.

[4] Powell, T., Soil texture effect on nitrate leaching in soil percolates. Soil and Plant Analysis Anal., 25(13\&14), pp. 2561-2570, 1994.

[5] Ferguson, R.B., Shapiro, C.A., Hergert, G.W., Kranz, W.L., Klocke, N.L. \& Krull, D.H., Nitrogen and irrigation management practices to minimize nitrate leaching from irrigated corn. Journal of Production Agriculture, 4(2), pp. 186-192, 1991.

[6] Filintas, T.Ag., Cultivation of Maize in Greece: Increase and Growth, Management, Output Yield and Environmental Sequences, Department of Environmental Studies, University of Aegean, Mitilini, Greece, 2003.

[7] Greek National Statistical Organization, Monthly Statistical Bulletin, Vol. 47, No. 8, Athens, 2002.

[8] Doorenbos, J. \& Kassam, A.H., Yield response to water. FAO Irrigation and Drainage Paper No. 33 FAO, Rome, 1986.

[9] Musick, J.T. \& Dusek, D.A., Irrigated corn yield response to water. Trans. ASAE, 23, pp. 92-98, 103, 1980.

[10] Zarogiannis, V., Beregnung und Standraum bei Mais (Zea mays L.). Fur Bodenkultur, in Wien, 30(3), pp. 281-303, 1979.

[11] Filintas, Ag., Dioudis, P., Koutseris, E. \& Papadopoulos, A., Irrigation water management effects in corn yield and environmental aspects. Proc. of First International Conference on Environmental Management, Engineering, Planning and Economics (CEMEPE/SECOTOX), Skiathos Island, Greece, Vol. II, pp. 1061-1066, 2007.

[12] Filintas, Ag., Dioudis, P., Koutseris, E. \& Papadopoulos, A., Soils nitrates GIS mapping, irrigation water and applied $\mathrm{N}$-fertilizer effects in soils nitrogen depletion in a drip irrigated 
experimental field in Thessaly basin. Proc. of 3rd IASME/WSEAS International Conference on Energy, Environment, Ecosystems and Sustainable Development (EEESD'07), Agios Nikolaos, Crete Island, Greece, pp. 487-492, 2007.

[13] Dioudis, I.P., Filintas, T.Ag. \& Papadopoulos, H.A., Corn yield in response to irrigation interval and the resultant savings in water and other overheads. Irrigation and Drainage Journal, DOI: 10.1002/ird.395 (in production), 2008.

[14] Filintas, T.Ag., Dioudis, I.P., Pateras, T.D., Hatzopoulos, N.J. \& Toulios, G.L., Drip irrigation effects in movement, concentration and allocation of nitrates and mapping of nitrates with GIS in an experimental agricultural field. Proc. of 3rd HAICTA International Conference on Information Systems in Sustainable Agriculture, Agroenvironment and Food Technology (HAICTA'06), Volos, Greece, pp. 253-262, 2006.

[15] Rench, E.W. \& Shaw, R.H., Black layer development in corn. Agron. Journal, 63, pp. 303-305, 1971.

[16] Danalatos, G.N., Quantified Analysis of Selected Land Use Systems in the Larissa Region, Greece, PhD Thesis, Agricultural University, Wageningen, pp. 133, 175-207, 1992.

[17] Hatzopoulos, N.J., Topographic Mapping, Covering the Wider Field of Geospatial Information Science \& Technology (GIS\&T), ISBN-10: 1581129866, ISBN-13: 9781581129861, Universal Publishers, 2008.

[18] Isaaks, E.H. \& Srivastava, R.M., Applied Geostatistics, Oxford University Press: New York, 1989.

[19] Goovaerts, P., Geostatistics for Natural Resources Evaluation, Oxford University Press: New York, 1997.

[20] Mass, S.J., Remote sensing for agriculture in the next decade. Proc. Beltwide Cotton Conference, eds P. Dugger \& A.D. Richter, National Cotton Council of America: San Diego, CA; Memphis, TN, pp. 36-38, 1998.

[21] Whelan, B.M., McBratney, A.B. \& Boydell, B.C., The impact of precision agriculture. Proc. of the ABARE Outlook Conference, 'The Future of Cropping in NW NSW', Moree, UK, 1997.

[22] Enviromental Sensors Inc. (ESI), MP-917 Soil Moisture Instrument Operational Manual, ESI: Canada, 1997.

[23] ESRI, Standard classification schemes. ArcGIS Desktop Manual, ESRI: USA, 2007. 